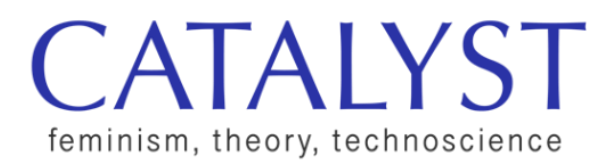

\title{
Mental Health and the Self-Tracking Student
}

\author{
Lindsay Weinberg \\ Honors College, Purdue University \\ Iweinber@purdue.edu
}

\begin{abstract}
This article examines universities' adoption of WellTrack-a self-tracking mobile phone application modeled on cognitive behavioral therapy techniques-as a solution to reported increases in the prevalence and severity of student mental health conditions. Drawing from a feminist materialist perspective that understands discourse and the material word as co-produced, this article argues that the app's design, marketing, and reception are deeply intertwined with the political rationality of neoliberalism, which centers self-responsibility and the market economy. The article first situates the development of the WellTrack app within larger institutional and political shifts towards digital education governance. It then contextualizes the app's use within the history of college mental health services in the United States, revealing how longstanding sociomedical discourses concerning student wellness individualize structural and systemic factors of ill health. Through close reading and immanent critique of the marketing and media reception of the WellTrack app's introduction into universities, the article provides an account of how universities are socializing students to relinquish data to private firms in exchange for health services. Students are encouraged to engage in constant self-examination and strive towards a vision of student wellness that precludes an analysis of the structural conditions and intersecting oppressions contributing to poor student mental health. These conditions are social and pervasive, requiring institutional analysis and critique of the university itself.
\end{abstract}

Weinberg, Lindsay. 2021. "Mental Health and the Self-Tracking Student." Catalyst: Feminism, Theory, Technoscience 7 (1): 1-26. 


\section{Introduction}

Mental health and student wellness occupy an increasingly central role in discussions about the future of higher education. Colleges across the United States are reporting increases in the prevalence and severity of mental health conditions (Lipson, Lattie, and Eisenberg 2018). A recent 2018 study of more than 2,000 graduate students in twenty-six countries found that PhD students suffer from anxiety and depression at rates that far exceed the general population (Evans et al. 2018). Both graduate and undergraduate students from racial, ethnic, gender, and sexual minority groups experience disproportionately higher rates of poor mental health outcomes, due to factors that include cultural stigma, discrimination, and a lack of adequate access to resources and structures of support (see, for example, Lipson et al. 2018; Lipson et al. 2019; Liv et al. 2019). This article focuses on universities' adoption of WellTrack as a solution to this mental health crisis.

WellTrack is a mobile phone application modeled on cognitive behavioral therapy techniques. It is designed to help users assess and track their own mental health, learn about the causes of anxiety and depression, and utilize the application's selfhelp tools. WellTrack is a subsidiary of CyberPsyc Software Solutions, Inc., a private company based in Canada and founded in 2010, which aims to capitalize on the expanding market for anxiety and depression treatment in the North American economy. This market is valued at an estimated $\$ 46$ billion each year. CyberPsyc's clients have included companies such as HCL America, as well as several public universities in the United States and Canada, including Georgia State University, the University of Miami, Ohio University, the University of California, Santa Cruz, Purdue University, Ball State University, Montana State University, Ryerson University, York University, and the University of Alberta.

The WellTrack application is part of the larger movement towards self-tracking for daily life management, given the ways its design facilitates users' repetitive documentation of their thoughts, moods, and behaviors for the purposes of mental health self-improvement. While there has been a great deal of critical scholarship on the quantified self movement within surveillance studies, media studies, and, more recently, feminist studies, less scholarly attention has been given to the use of self-tracking applications for student wellness. Deborah Lupton defines the quantified self as "the practice of gathering data about oneself on a regular basis and then recording and analyzing the data to produce statistics and other data (such as images) relating to one's bodily functions and everyday habits" $(2013,25)$. The concept was originally introduced by Wired editors Gary 
Wolf and Kevin Kelly in 2007, who sought to build a network of users seeking selfknowledge through tools for self-tracking (De Moya and Pallud 2017). These selftracking practices have been popularized through digital technologies such as wearables and mobile phone applications. Within the critical scholarship on selftracking through digital technologies, self-tracking has been understood as a neoliberal practice of self-management and self-surveillance (Lupton 2015; Hammarfelt, Rijcke, and Rushforth 2016; Ajana 2017), a site of concern regarding privacy, third-party data exploitation, and a loss of autonomy (Lanzing 2016), and a fantasy of biocontrol over the self (Andrieu 2015). Vassilis Charitsis (2019) points out that, in cases where self-tracking is institutionalized as part of corporate wellness plans, it can have discriminatory effects on those who cannot produce "good" data due to their class position and/or ability. And yet, dataism, the ideology that data provides objective truth, often frames self-tracking in neutral and even emancipatory terms (Charitsis 2019).

Feminist critiques of self-tracking have emphasized how self-tracking apps are bound up with normative assumptions about the body, gender identity, and gender roles (En and Pöll 2016; Fotopoulou 2016; Wernimont 2018), as well as how male designers frequently omit self-tracking parameters relevant to women's fertility and sexuality (Eveleth 2014). Furthermore, Aristea Fotopoulou (2016) has argued that through self-tracking, information from women's bodies produces additional surplus value under digital capitalism. As Boka En and Mercedes Pöll (2016) explain, self-tracking is deeply imbricated in systems of power and normative social structures, which shape the conditions of possibility for people's behaviors and choices. Most recently, Rosalind Gill (2019) has argued for the need to put feminist surveillance studies in conversation with media and cultural studies in order to highlight the ways that self-tracking apps encourage gendered forms of self-surveillance within postfeminist culture, which mobilize notions of freedom, agency, and empowerment to encourage women to self-monitor, from makeover and dieting apps, to menstruation and fertility apps.

This article responds to the call of this special issue asking scholars to consider how self-tracking technologies are situated within larger dynamics of societal change, and particularly, the neoliberal restructuring of medicine and public health, through feminist and intersectional perspectives. Drawing from a feminist materialist perspective that understands discourse and the material world as coproduced (En and Pöll 2016), this article argues that the app's design, marketing, and reception are deeply intertwined with the political rationality of neoliberalism, which centers self-responsibility and the market economy. While 
WellTrack does not specifically target women-identified users, it is symptomatic of the ways that self-tracking apps increase opportunities for digital selfsurveillance, "reinforcing the rationality of relentless self scrutiny which is a feature of postfeminist and neoliberal culture" (Gill 2019, 149). The WellTrack app typifies how notions of choice, agency, and empowerment are used to associate self-surveillance with a form of self-care that neither acknowledges the structural forces contributing to student mental health issues, nor is oriented towards structural change. Structures of oppression impact and condition student wellness, and yet these forces are obfuscated by the WellTrack app's design, which emphasizes individual behavior disarticulated from social structures of power. As Sasha Costanza-Chock explains, "intersecting inequalities are manifest at all levels of the design process, including (but not limited to): designers, intended users, values, affordances and disaffordances, scoping and framing, privileged design sites, governance, ownership, and control of designed objects, platforms and systems, and narratives about how design processes work" (2018, 4). This article thus investigates the ways that intersecting inequalities are reproduced through the WellTrack app's affordances and disaffordances, presuppositions about its users, embedded values, and data collection practices, with an emphasis on how the experiences and circumstances of those "marginalized by current power configurations" (D'Ignazio and Klein 2016) are rendered outside the frame of WellTrack's design considerations.

First, I situate the development of the WellTrack app within larger institutional and political shifts towards digital education governance internationally. I then contextualize its use within the history of college mental health services in the US, revealing how longstanding socio-medical discourses concerning student wellness work to individualize what are often structural and systemic factors of ill health. Next, using immanent critique and a close reading of WellTrack as both a media object and mediating process, I identify the underlying assumptions and contradictions within the design, marketing, and media reception of the WellTrack app's introduction into North American universities under neoliberalism, providing an account of the ways that public universities are rationalizing the proliferation of digital technologies across multiple spheres of life. Immanent critique, as a critical methodology, requires mapping the forms of belief, understanding, and evaluation that constitute social reality, and identifying discrepancies between underlying assumptions and concrete social practices in order to transform processes of social domination (Stahl 2013). Thus, the focus of my analysis is to map the ideological assumptions and values embedded in the promotional discourses and design of the WellTrack app itself alongside the 
concrete social, political, economic, and historical forces underpinning its development and implementation in the context of higher education. Ultimately, I show how the app's design, and the promotional discourses that shape its reception, encourage students to engage in constant self-examination and to strive towards a vision of student wellness that precludes an analysis of the structural conditions and intersecting oppressions contributing to poor student mental health, such as austerity and racism. These conditions are social and pervasive, requiring an institutional analysis and critique of the university itself.

\section{Digital Education Governance and Student Mental Health Services}

The primary set of social and historical circumstances shaping the introduction of recent digital tools, such as WellTrack, into North American universities is the governance strategies and political ideologies of neoliberalism, and corresponding economic liberalization policies, including austerity, privatization, and deregulation. When state government support declined, publicly subsidized higher education came to be supplanted by a greater reliance on tuition payments (Cottom 2017). Christopher Newfield (2016) has demonstrated how privatization is driving the increasing costs of public higher education, resulting in tremendous debt for students and their families, the outsourcing of university services to forprofit vendors, administrative growth, and a gravitation towards research that promises financial returns rather than increased public good. Instead of policy that reverses these trends, a range of data-driven tools for education management, pedagogy, and policymaking have emerged as vehicles for universities to both increase retention and cheapen undergraduate education in order to counteract a lack of public funding sources and preserve their rankings in the education market. Ben Williamson (2018) has documented the diffusion of partnerships between university administrators, researchers, education technology companies, policymakers, and international organizations for restructuring higher education practices around the production of digital data. This datafication of higher education, as Neil Selwyn explains, is part of the alignment of higher education with neoliberal ideology and policy, including "new regimes of accountability and internal controls in the form of monitoring techniques" (2014, 113).

Neoliberal austerity measures have increased pressures on US universities to focus on monitoring students to improve retention outcomes, given the proliferation of performance funding policies, which tie the release of state 
funding to selected student outcomes rather than enrollment rates (Hillman 2016). Furthermore, there is rising interest on behalf of OECD countries to measure and target the psychoemotional aspects of education in order to nudge students to develop the personality traits and socio-emotional qualities believed to lead to "grit," "resiliency," and "robot-proof" skills in the face of volatile labor markets. These efforts are largely based on an assumption, rooted in behavioral economics, that students will not make rational self-interested decisions for sufficiently meeting academic demands, and instead behave according to "emotions, habits, and other noncognitive processes" (Williamson 2019, 7). These trends in higher education policy and governance help explain what makes mental health apps like WellTrack attractive to university administrators: it encourages students to engage in the forms of mental health self-management that the app promotes, rather than increasing resource-intensive on-campus counseling services. In his sales email to me, Steve Jenkins (2019), sales development representative for WellTrack, explicitly positions the app as a solution to the problem of the "overutilization" of campus mental health resources. However, the institutional imperative to retain students has consistently shaped ideas of student wellness using individualist and depoliticizing disciplinary frameworks, beginning with the early college health programs of the twentieth century.

In contrast to late nineteenth-century conceptions of mental illness at universities, which treated poor mental health as a spiritual or moral deficiency for faculty or clergy to address (Kraft 2011), the mental hygiene movement of the twentieth century focused on individual maladjustment to environmental factors. This discursive shift produced the idea that students suffered from "personality development" problems, which resulted in well-qualified applicants leaving school and failing to complete their studies (Kraft 2011, 478). Princeton University created the first dedicated mental health service for students with "personality development" problems in 1910. From the inception of mental health services for students, retention was a primary concern and framing device for understanding how students could be harmed and healed.

The focus on retention in early student mental health services is typified by American psychiatrist Frankwood Williams's 1921 address at the first meeting of the American Student Health Association. Williams stressed the importance of student retention, the minimization of student "inefficiency," "mediocrity," and "unhappiness," and the need for social control as reasons for establishing mental health programs in colleges $(1921,301)$. These points of emphasis speak to the ways that socio-medical discourses produced ideas of a healthy student, which 
corresponded to an institutional interest (retention) as well as dominant ideas of workplace discipline (efficiency and self-control) in order to generate docility and compliance with university expectations. Additionally, for Williams, political radicals on college campuses were "university casualties" whose "mental integrity" was open to question (300). He created a clear separation between the individual, whose emotional impulses needed to be treated and managed, from the social situations in which these impulses were being expressed (300). As Sol Cohen explains, "the mental hygiene movement was basically conservative in its emphasis on the individual and in its turning away from social or political change...There was no need for major social overhaul or institutional change. The problems facing the nation were those of individual personality" $(1983,141)$. Student activism would go on to surge in the 1920 in response to gender-and race-based segregation on college campuses, mandatory daily chapel, and room inspections, particularly at historically Black institutions (Wolters 1975). This early history of college mental health highlights the university's complicity in systems of oppression through the mobilization of mental health discourses that aligned with dominant institutional interests. Today, university ideas of wellness continue to socialize students to think of mental health as a matter of individual, personal responsibility disconnected from social structural forces, and this is captured in the development and use of WellTrack.

\section{WellTrack and Subjectivation}

The WellTrack app encourages students to self-manage moods, thoughts, and behaviors using digital technology in order to cope with feelings of anxiety and depression. The app is thus a technology of subjectivation, where students' selfunderstanding of their own wellness is produced, in part, through their interaction with the application and the application's metrics. Metrics, as David Beer explains, "shape the ways that the social world is understood, approached, and how the people that constitute it are classified and categorised" $(2016,71)$. Thus, these metrics inform how students understand desirable health outcomes in the context of rising rates of student mental health struggles in higher education, or, in other words, how students are subjectivated.

Subjectivation is "a complex set of processes whereby one's sense of self as an individual agent is paradoxically shaped according to processes and forces external to the self. Such factors include not only race, class, and gender, of course, but also social norms, educational circumstances, labor potential, and health" (Langlois and Elmer 2019, 237). As I will demonstrate, the WellTrack app helps to produce ideas and practices of self-knowledge that are influenced by 
dominant institutional imperatives under neoliberalism, which discount structural factors of ill health, including social and economic inequality, and instead promote individualized practices of self-care. It is through ideas of how to care for oneself that individuals come to internalize norms for what is deemed appropriate conduct (Foucault 1986). To be a "good" student is to pursue self-knowledge with the aim of being responsible and self-regulated.

Rather than understanding users and technologies within a subject-object dichotomy, subjectivation emphasizes how users come to know and understand themselves through relationships with technology that are shaped by social and historical forces. This requires reading WellTrack not purely as a media object but as a set of mediating processes, "which are simultaneously technical and biological, social and political" (Wernimont 2018, 7). According to Sarah Kember and Joanna Zylinska, processes of mediation allow for "understanding and articulating our being in, and becoming with, the technical world, our emergence and ways of interacting with it, as well as the acts and process of temporarily stabilizing the world into media agents, relations, and networks" $(2012, x v i)$. Thus, WellTrack's emphasis on generating subjects who engage in voluntary, individual, mental health self-management is best understood as existing within a constellation of structural forces, discourses, and technological and embodied practices, including what Patricia Clough calls "biopolitical networks of disciplining, surveillance, and control" $(2007,3)$.

WellTrack's emphasis on individual self-management is apparent in university press releases and news reports regarding the adoption of the application. For instance, Emily Mertz (2018) from Global News describes how the "Canadianmade wellness platform is helping students at the University of Alberta become more aware of and engaged in their own mental health." Students are encouraged to monitor themselves, and this act of self-monitoring is conceptualized as responsible self-governance and mental fitness (Quinn 2016). In the case of Jodie Vanderslot's (2017) write-up in York University's community newspaper, Excalibur, the WellTrack application is presented as a solution to the fact that healthcare costs are on the rise, as is demand for mental health care, and so the app can reach students "in a way that may not otherwise be possible." The rising costs of healthcare, the increasing demands for mental health resources, and the resource limitations are presented here as barriers that are not "possible" to transcend, and yet technology is presented as an immediate solution. As Gaya Arasaratnam, acting director of strategic projects for student health and wellness at Ryerson University, asserts, "if a student needs help at 10 p.m., they can get it 
instantly with WellTrack" (quoted in Zalcmanis-Lai 2016). Students who do not have the resources or time, who feel stigmatized in seeking out help, or whose universities have extended waiting lists can instead turn to a mobile phone application for assistance. These are barriers that vulnerable students, and particularly low-income students, students of color, queer, and gender nonconforming students, disproportionately face due to existing inequalities in health services and outcomes, which are compounded by the financial limits of existing campus wellness resources (Dunbar et al. 2017; Lipson et al. 2018).

It is important to note the ways that "vulnerability" is often invoked within dominant institutional discourses in patronizing, stigmatizing, and oppressive ways, including for the purposes of legitimating "selective systems of welfare, paternalism, and social control" (Brunila and Rossi 2017, 289). The discourse of vulnerability is frequently used to turn structural marginalization into a matter of personal responsibility and individual failure, "which can then be rectified through micro-management" (McLeod 2012, 19) and/or self-discipline (Brunila and Rossi 2017, 293). However, unlike neoliberal vulnerability discourses, I invoke vulnerability here as a social and situational position (Brunila et al. 2016), precisely to stress the ways that structural forces differentially condition and impact students' mental health. While a readily available mental health app may in theory help mitigate access barriers, given that it is offered to university students at no additional cost and available on demand, the majority of university students across demographics have access to a smartphone (Pew Research Center 2019), and the app is compatible with screen-readers for visually impaired users, it is important to critically attend to the type of therapeutic care that the application offers. This includes evaluating the relationship between therapeutic care and desired subjectivating practices under neoliberalism, as well as whether the therapeutic techniques on offer account for, and address, structural factors impacting students' mental health.

\section{CBT and Neoliberalism}

While cognitive behavioral therapy (CBT), the therapy on which the app is modeled, has been shown in some studies to be an effective treatment for symptoms of depression and anxiety (see, for example, Driessen and Hollon 2010), the overall efficacy of CBT is greatly contested (Ferraro 2016).

Furthermore, CBT delivered through low-cost, online measures involving selfadministration and mindfulness techniques have been shown to have "high dropout rates" and "no long-term benefits" (So et al. 2013), and yet is increasingly advocated for in a range of institutional contexts, including schools, workplaces, 
and prisons (Ferraro 2016, 20). Even prior to CBT's digital proliferation, its design as a therapeutic technique has been consistently compatible with the political imperatives of neoliberalism. Psychiatrist Aaron T. Beck's development of CBT in the 1970 coincided with new demands from the US Congress and insurance companies for "quantitative proof of therapy's efficacy and cost-effectiveness" (Rosner 2018, 43), in tandem with rising healthcare costs and the increasing power of private health insurance companies in the US. CBT provided an understanding of pathology and standardized therapeutic practices that allowed for the "empirical investigation of the patient's automatic thoughts, inferences, conclusions, and assumptions" (Rosner 2018, 35). This therapeutic framework was offered in response to political and economic pressures for psychotherapy to adopt hyper-rational forms of assessment, and particularly, randomized control trials and actuarial modeling. CBT has also been critiqued within contemporary clinical psychology debates as a highly individualized form of treatment under neoliberalism. For instance, Asa Jansson (2017) argues that CBT is one of the favored treatments for affective disorders under neoliberalism because "an individualised, neurobiological model of psychological distress sits comfortably within a political framework that emphasises individual responsibility and choice over social support." Similarly, David Ferraro argues that CBT is grounded in an individualist, disciplinary approach that seeks to "inculcate correct thinking, behaviour, and self-observation...applicable to anybody and amenable to administration by a computer programme" $(2016,9)$.

This compatibility between the therapeutic protocols of CBT and the political framework of neoliberalism, and particularly their shared emphasis on "soft policing" (Ferraro 2016, 19), is evident in the WellTrack's self-described key function, the "MoodCheck." As Lupton explains, neoliberal political rationalities "generally rely on apparatuses of 'soft' rather than 'hard' power. Instead of relying on coercive measures that appear to be imposed from above, in managing and regulating their citizens neoliberal political systems invest faith in the voluntary take-up of imperatives by the citizens themselves" (2016b, 50). In the case of WellTrack, users receive daily nudges to log their mood and provide a description of what is on their mind. To document their mood, the user drags a circular icon until it lands on the emoji that they feel best captures their mood. There are also options to select corresponding words for the mood, such as "wonderful," "excited," "happy," "stressed," "tired," "overwhelmed," and "I don't know." The user then indicates what they are currently doing, whom they are with, and their location. This information is used to produce a data point on a "Mood Heatmap," which shows the user how their current mood compares to past logged moods. 
This form of mapping, like other self-tracking techniques, allows the user to make sense of their mental health through a represented and externalized visual representation. In this way, as Matthias Bode and Dorthe Brogård Kristensen explain, "self-trackers can feel like looking into connections and correlations between different aspects of their life. In order for that to work, however, they have to be very careful to track every day in order to be able to make aspects of the self visible and transparent, and consequently turn it into data visualisation and correlations" $(2015,127)$. Thus, the mood mapping function, and the promise of greater data-driven insights into the self, persuades users to engage in selfmanagement and to routinely invest time, attention, and information into the application. Additionally, as feminist human-computer interaction scholars have pointed out, self-tracking designers and engineers frequently rely on reductionist categories, such as "mood scores," because they are easily trackable through data (Cerci 2018). A feminist approach to data visualization, in contrast, would "consider how diverse contexts can influence the production of a visualization" (D'Ignazio and Klein 2016, 3) and ask designers to grapple the ways that power and oppression shape design and data visualization processes (D'Ignazio and Klein 2016). This is not the case with WellTrack, which relies on a discrete, trackable unit-a mood in a given moment in time-that is abstracted from any account of the structural forces contributing to student mental health outcomes.

If we consider the WellTrack app not in isolation, but as a mediating process produced and applied within a constellation of socio-material forces, we must attend to the ways WellTrack is tangled up with broader power relations and neoliberal shifts in the structure of the university, work, and capitalism. For instance, WellTrack's emphasis on digital self-care and self-monitoring mirrors the marketing of data-driven surveillance technologies in emerging corporate wellness and interactive life insurance programs, which produce data that can be sold for refining target advertisements, products, and services, as well as empower companies to enact punitive consequences for users who do not, or cannot, exercise, eat well, or sleep well (Gidaris 2019). The implications of this parallel are that WellTrack socializes students to participate in the same datadriven rhythms of engagement that not only serve the immediate institutional imperatives of higher education, but also sustain extractive forms of capital accumulation in the digital economy.

Phoebe V. Moore (2018) has argued that forms of self-tracking that occur outside the formal confines of the workplace have been increasingly incorporated into it. While students are being encouraged to self-track for enhanced mental wellness, 
and expected to demonstrate affects of resilience, flexibility, and grit under conditions of rising social and economic precarity (Webster and Rivers 2019), technologized management systems are demanding that workers self-track their behaviors, attitudes, moods, stress levels, and practices for the purposes of increasing their agility and flexibility (Moore 2018). These digitization methods, which quantify affective and emotional labor, have been shown to lead to "high turnover rates, workplace rationalisation and worker stress and anxiety" (Moore $2018,3)$, which Moore links to rising levels of both objective and subjective precarity. In both cases, the affective capacities of students and workers are being channeled towards developing what neoliberal capitalism requires: "the desires and habits necessary for it to perpetuate itself" (Read 2010, 114). Furthermore, Jenkins (2019) writes that, "universities are typically early adopters of technology so there is a chance that the successes that these universities have may trickle over into the corporate world. Especially as students become tomorrows [sic] employees." Jenkins links, quite explicitly, enhanced student wellness with enhanced corporate gains. This framing is in keeping with larger international trends in higher education that seek to equip young people with emotional management skills so that they become more "accountable" for their role within the labor market under rising conditions of economic precarity (Brunila and Rossi 2017).

\section{WellTrack, Structural Racism, and Austerity}

WellTrack's emphasis on individual self-care and accountability is just one way in which the app serves to disconnect student mental health from structural factors. In the application's "Cognitive Distortions Quiz," the expressed purpose of which is to help students understand the different thinking styles that WellTrack deems "unhelpful," it becomes clear that WellTrack has embedded presuppositions about its users, which fail to account for the ways that economic and racial inequalities inform students' life experiences. For instance, the second quiz question reads as follows:

Natalie is leaving a store without having purchased anything. As she is about to pass through the anti-theft devices at the door, she thinks, "What if the alarm sounds, even though I haven't taken anything? What is the security comes and they accuse me of stealing? What if I'm treated like I did something wrong?" What kind of distortion is Natalie using?

According to the app, Natalie is engaging in "catastrophizing-she is imagining an unlikely and extreme scenario, which is then causing her to feel anxious." The app 
then presents an example of an undistorted thought in the given scenario: "I havent' [sic] taken anything from the store, so the alarm won't sound." What this quiz question reveals is that, either the unmarked student the application has in mind is white, or the designers of the application's quiz function are not aware of the routine forms of discrimination, intensified conditions of surveillance, and higher rates of police violence that people of color face. Simone Browne (2015), Dorothy E. Roberts (2019), and Ruha Benjamin (2019) have stressed how surveillance is a key technology of racial oppression, from the transatlantic slave trade to the present system of mass incarceration. People of color are frequently racially profiled and criminalized during routine, everyday encounters with surveillance workers, such as security guards, and African Americans file the majority of false arrest complaints in US retail settings (Gabbidon 2003). The app reinforces the message that what might be a legitimate response to structural conditions of racism and inequality is in fact a cognitive distortion.

The app's emphasis on individual behavior and thought is consistent with neoliberal political rationalities, wherein "social structural factors that influence people's living conditions and life chances-such as social class, gender, geographic location, race and ethnicity-are discounted in favour of the notion that people are self-made" (Lupton 2016b, 50). Thus, the WellTrack app fails to engage with how intersecting inequalities inform psychosocial thought and behavior. This function is not unique to WellTrack, but rather a common feature of design practices that take race-, gender-, and class-neutral approaches, which often upholds systems of oppression (Costanza-Chock 2020). For instance, Madisson Whitman has noted in her ethnographic study of predictive analytics for tracking student success that the removal of demographic markers in predictive models in order to focus on individual behaviors that "students can change," such as engagement with learning management systems and class attendance, "enables the institution to transfer the burden of success away from itself and keep the tacitly held knowledge of inequality out of the university's visions for predictive modeling" $(2020,2)$.

This example of Natalie is thus a symptom of an underlying problem with WellTrack's design, as well as with broader digital education governance practices that understand students as separate from their corporeality as raced, classed, and gendered subjects, and abstracted from the socio-structural contexts that inform their lived reality. In the case of WellTrack, the app provides no explicit guidance for students experiencing structural and interpersonal racism on campus. Mismatch theory, grounded in racist assumptions about aptitude, argues 
that students of color are harmed by policies such as affirmative action because they are then matched with schools that are too competitive for them. Some mental health experts have suggested that Black students "who strive to simultaneously excel in the classroom and disprove the mismatch theory might ultimately overwork themselves to the point of illness" in order to demonstrate intellectual worth (Green 2016). Universities across the US, which are rooted in histories of racial-colonial oppression (Wilder 2013), are persistently sites of discrimination, xenophobia, tokenism, and surveillance for students of color (McGee and Stovall 2016). Living in a society constituted by white dominance has corporeal and mental effects that go unaccounted for in dominant race-neutral discourses concerning individual students' "grit" and "resiliency" (McGee and Stovall 2015). As Ebony O. McGee and David Stovall explain, "the consequences of racial discrimination cannot be fully mitigated by well-established coping strategies... Only the eradication of racism will alleviate race-related stress for African Americans and other historically racialized populations" (2015, 501). And yet, all psychic phenomena, within the WellTrack app, are matters of individual thoughts and behaviors that can be reduced to a set of cognitive distortions and unhelpful thinking patterns, rather than responses to the pervasiveness of racial and class oppression within higher education.

The WellTrack app operates within an institutional context shaped by both structural racism and austerity. Americans currently owe over $\$ 1.64$ trillion in student loan debt, which is roughly $\$ 587$ billion more than the total US credit card debt (Student Loan Hero 2020). Additionally, Black students borrow federal student loans at higher interest rates, borrow more at public colleges than other students, are more likely to need to take on debt to earn a college degree, and are more likely to have difficulty repaying student loans. These statistics reflect structurally racist employment, wage, and educational access disparities, which leads to families of color having fewer resources to pay exorbitantly high tuition rates at public universities. Black students have less generational wealth due to the history of slavery, redlining, and labor inequalities, are more likely to be the first in their family to go to college, make less money after graduation, and are more likely to drop out (Helhoski 2018). For many students of color, the impacts of racism on student mental health discussed above are thus compounded by experiences of financial precarity.

There is one instance in which debt is explicitly addressed in the app, and this is through the "Activity Scheduler" tool. This tool allows students to schedule activities that are categorized based on whether they are "Pleasurable," "Social," 
or "Achievement" oriented. For achievement activities, the list of provided examples includes doing household repairs, exercising, cleaning, returning library books, writing a thank-you note, and, paying debts. The app thus promotes students having a positive affective response to the act of paying into debt, a framing that hardly challenges the increasing rollback of public funds to support higher education, nor makes room for collective struggle against financialization (see, for example, Debt Collective 2020). Additionally, these listed examples account for limited duties beyond self-care, a common blind spot identified by feminist scholars who highlight how relations of care and mutual dependency are a constitutive feature of social life, and yet are masked within the classical, masculinist tradition of individualism (e.g., Kittay 1999).

These forms of individualizing self-care that WellTrack encourages students to adopt stand in stark contrast to the self-care practices envisioned by Black feminist scholar Audre Lorde (1988) in the epilogue of A Burst of Light. Lorde situates self-care as a strategy of resistance against the intersecting forces of oppression that shape the lives of marginalized people. She writes, "caring for myself is not self-indulgence, it is self-preservation, and that is an act of political warfare" (130). In Lorde's formulation, self-care cultivates a combative form of resilience in the face of power dynamics that seek to stifle one's ability to survive. It is important to heed Sara Ahmed's (2014) warning about treating all forms of self-care as inherently neoliberal, which collapses the distinction between selfcare practices indebted to the tradition of Black feminism with the forms of selfcare that perpetuate the dominant socioeconomic paradigm. In the case of WellTrack, however, the app promotes an understanding of self-care that is separated from an account of the social and economic forces contributing to mental illness, and which disproportionately harm marginalized students. And yet, rising levels of precarity under neoliberalism are what "generalises effects of insecurity that increase the drive to regulate and predict" (Moore 2018, 119).

\section{Data Capture and Consent}

WellTrack's design for self-tracking, like most digitized commercial self-tracking apps, doubles as a form of capitalist dataveillance, or "the watching of people using technologies that generate data, increasingly in digitized formations" (Lupton 2016a, 103). While users of this app engage in self-care in that they record information about themselves in order to optimize and improve their mental health, the app also monitors and collects information about users for commercial gain. Commercial mental health apps like WellTrack thus extend biocapitalism, the extraction of revenue from human bodies (Rajan 2012), into the domains of 
thought, mood, behavior, and physical sensations of anxiety and depression, all of which WellTrack asks users to document. It is thus useful to apply CostanzaChock's design justice framework, which asks that we interrogate "what happens to the profits, attribution, and governance of the designed object or system" $(2018,11)$ in order to attend to the ways that the app's design can reproduce existing inequalities. WellTrack's deployment of dataveillance raises issues concerning student privacy and data exploitation that dominant notions of consent, enshrined in privacy policies, do not address.

Feminist scholars have powerfully critiqued the discourse of consent that has come to dominate universities in the context of sexual violence on campus in ways that can also highlight the problems of privacy policies grounded in notions of consent, and particularly the assumption that "consent is equally and universally accessible" (Graybill 2017, 175). As Rhiannon Graybill's intersectional feminist critique of consent discourse notes, the assumption of the autonomous liberal subject within consent discourse overlooks the ways that subjects are differentially impacted according to race, gender, disability, and sexuality, which produces unequal conditions and consequences for saying "yes" or "no" to sex $(2017,175)$. In the case of deciding whether to use WellTrack, regardless of the app's limitations, it provides a health service to students at no additional cost. Those who are most vulnerable and unable to access alternative care are in less of a position to forego using the service. Furthermore, the term privacy policy is misleading. These contracts between users and companies do not guarantee that the user's data will be kept private, but instead stipulate what information a given business gathers and how they collect, use, and/or share that information with others. This speaks to what a range of feminist scholars, social theorists, and critical legal scholars have long demonstrated: that traditional understandings of privacy do not account for the ways privacy intersects with relations of power and inequality (Gilliom 2001, 121-25). WellTrack introduces users to third-party vendors and websites, which may deposit cookies on the user's computer, and the privacy policies of which are not under their control (CyberPsyc Software Solutions 2019). Thus, WellTrack is symptomatic of ways that the larger tech industry "normalizes its practice of unethically sharing private customer health information with unknown third parties through its Terms of Service/Use contracts and Privacy Policies" (Hutchinson and Novotny 2018, 106). If student data is being collected, anonymized or not, for the purposes of sale or marketing, this means that the domain of students' thoughts, moods, and behaviors is directly involved in private companies' profit-making mechanisms by virtue of using a university mental health service. Consent discourse sets the bar too low in 
its fixation on consent as the only measure of the "good," often precluding conversations about pleasure, in the case of sex (Graybill 2017), and justice, in the case of technology.

Certainly, there are aspects of WellTrack that provide useful information for students and tools they might find helpful. However, it is important to situate these tools within the larger sociopolitical context of the application's use, as well as the app's relationship to dataveillance. For example, there is a "Zen Room," which facilitates meditation sessions, complete with a range of ambient noises to choose from, as well as control over the sound volume and style of meditation. However, as Rosalind Gill and Ngaire Donaghue note, there is an irony with which "a set of techniques and practices developed from a tradition that is critical of Western achievement orientation, [are] now being enthusiastically embraced in an effort to soothe some of the harsh psychic consequences of the always-on, constantly striving, contemporary academic culture" $(2016,98)$. Furthermore, when students fill out the app's wellness exam, particular questions will provide students with campus-specific resources, depending on whether they click yes to questions such as, "are you experiencing academic difficulties?," and "are you worried about your financial situation and/or have concerns about your basic needs (housing/food/transportation)?" However, based on the student's wellness exam, they are referred to in-app modules, which result in further data collection. Thus, information about the resources that correspond to the user's potential needs, which are provided only notionally, is part of a trade-off in exchange for information that the private firm collects.

Part of the way the app is marketed to university administrators is through an emphasis on its ability to offer campus-specific resource information to students. The WellTrack website explains that universities can integrate their "on- and offcampus resources for academic, financial, health and wellness, substance abuse, safety and security, and sexual violence into WellTrack. Individual students will be recommended a customized suggestion based on which areas they indicate they need more support" (WellTrack 2020). This site-specific relevancy is similar to how other private firms have successfully established contracts with universities, despite privacy concerns (Sacks 2018). For example, in 2018, Saint Louis University became the first university in the United States to bring Amazon Alexa-enabled devices into every student residence hall room and student apartment on campus. This contract included the deployment of thousands of Echo Dot smart devices, customized to answer over one hundred questions specific to Saint Louis University. According to the campus's information officer 
David Hakanson, "the new tool can boost efficiency" (quoted in Montag 2018), helping students to get responses immediately, rather than having to search the web. Thus, not only ideas of relevancy but also increased efficiency help shape digital technology's integration into campus life.

Feminist scholars have pointed out the ways that dominant understandings of efficiency typically benefit those already in power (Frost 2016, 20). Thus, while the integration of more digital technology into universities might seem like a means of democratizing access to care, this assumption "leaves out a lot of ethical complexities" (Frost 2016, 18). Both the university and the firms that provide smart technology enact discretionary power when it comes to determining what questions about the university are answerable. In the case of a student who reportedly asked, "Hey Alexa, why is tuition so high?" Alexa replied, "Hm, I don't know that one" (Brown 2018). While universities give students the option of unplugging and storing the devices, this reduces concerns over privacy and data exploitation to a matter of individual choice. Additionally, to focus purely on whether students can remove the device is to overlook how specific technologies actively produce what is readily knowable to students about the university in the context of austerity, while normalizing the increasingly large role of for-profit companies within the infrastructures and operations of public higher education.

\section{Conclusion}

Based on the analysis above, it is not clear how WellTrack helps universities deliver what students report will be most beneficial to their mental health: the reduction of stigma, which requires collective action to redefine toxic cultural norms, and improved faculty and staff education about mental health issues (Simon 2017). While university contracts with CyberPsyc Software Solutions do not preclude these other forms of outreach, as demonstrated above, the notion of wellness the app facilitates is one that individualizes and depoliticizes student wellness such that structural marginalization becomes a matter of personal responsibility. It asks students to constantly self-monitor and self-manage their thoughts and behaviors in a software environment designed for data capture.

This focus on individual conduct produces a limited frame of what is possible to transform about higher education, sidestepping students' capacity to challenge the underlying socioeconomic, political, and institutional structures that impact mental health. If wellness app developers were to incorporate design justice principles, this could lead to the development of non-exploitative practices that limit the power of the app designer, and instead empower community members 
who will be directly impacted by the design process to direct its goals and outcomes (Costanza-Chock 2020,7-8). In the context of university wellness apps, this approach might include marginalized students directly guiding the design process, and ensuring that university community members committed to racial and economic equality have control over the distribution of its benefits. However, as Benjamin warns us, the rubric of design "could also sanitize and make palatable deep-seated injustices" (2019, 176).

WellTrack is now featured on several universities' counseling center resources for coping with stress and anxiety under COVID-19, and the pandemic will likely be leveraged to increase the diffusion of data analytics and private-public partnerships for digitally monitoring student behavior (Williamson 2020). Furthermore, as Jeremy Knox, Ben Williamson, and Sian Bayne note, "given the pervasive discourses of efficiency-savings that accompany the promotion of dataintensive technologies in education, it seems likely that less financially stable educational institutions will be those more inclined to adopt systems that offer cost-effective management of student cohorts" (2020, 42). The pandemic has compounded existing conditions of financial instability for many universities from decades of austerity and privatization. If universities are to be places that support students' mental health, technological solutionism-the reduction of complex social phenomena to neatly defined problems that can be "efficiently" solved for

and optimized using technology (Morozov 2013) -needs to be contested. Instead, efforts must engage with the necessary intersectional analyses, institutional critiques, and radical social and economic reforms for meaningfully addressing student mental health within a racially and economically unjust society. This includes collectively resisting universities' active deployment of neoliberal ideology and complicity in neoliberal policies, with disparate consequences for the university's most marginalized.

\section{Acknowledgements}

The author is grateful to the anonymous peer reviewers of Catalyst: Feminism, Theory, Technoscience, whose comments were tremendously generative and impactful on this manuscript's development. She would also like to thank Venla Oikkonen and Luna Dolezal for their supportive feedback, and Joanne Muzak for her precise and careful read of this manuscript during copyediting.

\section{References}

Ahmed, Sara. 2014. "Selfcare as Warfare." Feministkilljoys (blog). August 25, 2014. 
https://feministkilljoys.com/2014/08/25/selfcare-as-warfare/.

Ajana, Btihaj. 2017. "Digital Health and the Biopolitics of the Quantified Self." Digital Health no. 3, 1-18. https://doi.org/10.1177/2055207616689509.

Andrieu, Bernard. 2015. "L'osmose technique avec son corps viv@nt: Une auto-santé connectée du patient immersif." L'Évolution psychiatrique 81 (2): 253-65.

https://doi.org/10.1016/j.evopsy.2015.07.004.

Beer, David. 2016. Metric Power. London: Palgrave Macmillan.

Benjamin, Ruha. 2019. Race after Technology: Abolitionist Tools for a New Jim Code. Medford, MA: Polity Press.

Bode, Matthias, and Dorthe Brogård Kristensen. 2015. "The Digital Doppelganger Within: A Study on Self-Tracking and the Quantified Self Movement." In Assembling Consumption: Researching Actors, Networks and Markets, edited by Robin Canniford and Domen Bajde, 119-32. New York: Routledge.

Brown, Dalvin. 2018. "Alexa Goes to College: Echo Dots Move into Dorms on Campus. USA Today, September 6, 2018.

https://www.usatoday.com/story/money/2018/og/o6/college-students-echo-dotsdorm-rooms/1087251002/.

Browne, Simone. 2015. Dark Matters: On the Surveillance of Blackness. Durham, NC: Duke University Press.

Brunila, Kristiina, and Leena-Maija Rossi. 2017. "Identity Politics, the Ethos of Vulnerability, and Education." Educational Philosophy and Theory 50 (3): 287-98. https://doi.org/10.1080/00131857.2017.1343115.

Brunila, Kristiina, Elina Ikävalko, Tuuli Kurki, Katariina Mertanen, and Anna Mikkola. 2016. "Revisiting the Vulnerability Ethos in Cross-Sectoral Transition Policies and Practices for Young People in the Era of Marketisation of Education." Research in Comparative \& International Education 11 (1): 69-79.

https://doi.org/10.1177/174549991663106o.

Cerci, Sena. 2018. "Embodying Self-Tracking: A Feminist Exploration of Collective Meaning-Making of Self-Tracking Data." Master's thesis, Malmo University.

Charitsis, Vassilis. 2019. "Survival of the (Data) Fit: Self-Surveillance, Corporate Wellness, and the Platformization of Healthcare." Surveillance \& Society 17 (1/2): 13944. https://doi.org/10.24908/ss.v17i1/2.12942.

Clough, Patricia. 2007. Introduction to The Affective Turn: Theorizing the Social, edited by Patricia Clough and Jean O’Maley Halley, 1-33. Durham, NC: Duke University Press. 
Cohen, Sol. 1983. "The Mental Hygiene Movement, the Development of Personality and the School: The Medicalization of American Education." History of Education Quarterly 23 (2): 123-49. https://doi.org/10.2307/368156.

Costanza-Chock, Sasha. 2018. "Design Justice: Towards an Intersectional Feminist Framework for Design Theory and Practice." Proceedings of the Design Research Society. https://ssrn.com/abstract=3189696.

- 2020. Design Justice: Community-Led Practices to Build the Worlds We Need. Cambridge, MA: MIT Press.

Cottom, Tressie McMillan. 2017. Lower Ed: The Troubling Rise of For-Profit Colleges in the New Economy. New York: The New Press.

CyberPsyc Software Solutions, Inc. 2019. "Privacy Policy." Last modified May 2019. https://app.welltrack.com/privacy-policy.

Debt Collective. 2020. "End Student Debt!" https://strike.debtcollective.org/.

De Moya, Jean-Francois and Jessie Pallud. 2017. "Quantified Self: A Literature Review Based on the Funnel Paradigm." Proceedings of the 25th European Conference on Information Systems (ECIS), Guimarães, Portugal, June 5-10, 2017.

https://aisel.aisnet.org/ecis2017_rp/108

D'Ignazio, Catherine, and Lauren F. Klein. 2016. "Feminist Data Visualization." In IEEE Workshop on Visualization for the Digital Humanities (VIS4DH). Baltimore, MD.

Dunbar, Michael S., Lisa Sontag-Padilla, Rajeev Ramchand, Rachana Seelam, and Bradley D. Stein. 2017. "Mental Health Service Utilization among Lesbian, Gay, Bisexual, and Questioning or Queer College Students." Journal of Adolescent Health 61 (3): 294-301. https://doi.org/10.1016/j.jadohealth.2017.03.008.

Driessen, Ellen, and Steven D. Hollon. 2010. "Cognitive Behavioural Therapy for Mood Disorders: Efficacy, Moderators and Mediators." Psychiatric Clinics of North America 33 (3): 537-55. https://doi.org/10.1016/j.psc.2010.04.005.

En, Boka, and Mercedes Pöll. 2016. "Are You (Self-)tracking? Risks, Norms and Optimisation in Self-Quantifying Practices." Graduate Journal of Social Science 12, no. 2 (April): 37-57.

Evans, Teresa, Lindsay Bira, Jazmin Beltran Gastelum, L Todd Weiss, and Nathan L. Vanderford. 2018. "Evidence for a Mental Health Crisis in Graduate Education." Nature Biotechnology, no. 36, 282-84. https://doi.org/10.1038/nbt.4089.

Eveleth, Rose. 2014. "How Self-Tracking Apps Exclude Women." The Atlantic, December 15, 2014. https://www.theatlantic.com/technology/archive/2014/12/howself-tracking-apps-exclude-women/383673/. 
Ferraro, David. 2016. "Psychology in the Age of Austerity." Psychotherapy and Politics International 14 (1): 17-24. https://doi.org/10.1002/ppi.1369.

Fotopoulou, Aristea. 2016. Feminist Activism and Digital Networks: Between Empowerment and Vulnerability. London: Palgrave Macmillan.

Foucault, Michel. 1986. The Care of the Self: The History of Sexuality, Vol. 3. New York: Pantheon.

Frost, Erin A. 2016. "Apparent Feminism as a Methodology for Technical Communication and Rhetoric." Journal of Business and Technical Communication 30 (1): 3-28. https://doi.org/10.1177/1050651915602295.

Gabbidon, Shaun L. 2003. "Racial Profiling by Store Clerks and Security Personnel in Retail Establishments: An Exploration of 'Shopping While Black.'" Journal of Contemporary Criminal Justice 19 (3): 345-64. https://doi.org/10.1177/1043986203254531.

Gidaris, Constantine. 2019. "Surveillance Capitalism, Datafication, and Unwaged Labour: The Rise of Wearable Fitness Devices and Interactive Life Insurance."

Surveillance \& Society 17 (1/2): 132-38. https://doi.org/10.24908/ss.v17i1/2.12913.

Gill, Rosalind. 2019. "Surveillance Is a Feminist Issue." In The Routledge Handbook of Contemporary Feminism, edited by Tasha Oren and Andrea Press, 148-61. New York: Routledge.

Gill, Rosalind, and Ngaire Donaghue. 2016. "Resilience, Apps and Reluctant Individualism: Technologies of Self in the Neoliberal Academy." Women's Studies International Forum 54 (January-February): 91-99.

https://doi.org/10.1016/j.wsif.2015.06.016.

Gilliom, John. 2001. Overseers of the Poor: Surveillance, Resistance, and the Limits of Privacy. Chicago: University of Chicago Press.

Graybill, Rhiannon. 2017. "Critiquing the Discourse of Consent." Journal of Feminist Studies in Religion 33 (1): 175-76. https:doi.org/10.2979/jfemistudreli.33.1.22.

Green, Adrienne. 2016. "The Cost of Balancing Academia and Racism." The Atlantic, January 21, 2016. https://www.theatlantic.com/education/archive/2016/01/balancingacademia-racism/424887/.

Hammarfelt, Björn, Sarah Rijcke, and Alexander D. Rushforth. 2016. "Quantified Academic Selves: The Gamification of Research through Social Networking Services." Information Research 21 (2): 1-13.

Helhoski, Anna. 2018. "Why the Student Debt Crisis Hits Black Borrowers Harder." Nerd Wallet, February 7, 2018. https://www.nerdwallet.com/blog/loans/studentloans/black-student-debt-crisis/. 
Hillman, Nicholas. 2016. "Why Performance-Based College Funding Doesn't Work." The Century Foundation, May 25, 2016. https://tcf.org/content/report/whyperformance-based-college-funding-doesnt-work/?session=1.

Hutchinson, Les, and Maria Novotny. 2018. "Teaching a Critical Literacy of Wearables: A Feminist Surveillance as Care Pedagogy." Computers and Composition 50 (December): 105-20. https://doi.org/10.1016/j.compcom.2018.07.006.

Jansson, Åsa. 2017. "From Self-Help to CBT: Regulating Emotion in a (Neo)liberal World." The History of Emotions Blog. December 11, 2017.

https://emotionsblog.history.qmul.ac.uk/2017/12/from-self-help-to-cbt-regulatingemotion-in-a-neoliberal-world/.

Kember, Sarah, and Joanna Zylinska. 2012. Life after New Media. Cambridge, MA: MIT Press.

Kittay, Eva Feder. 1999. Love's Labor: Essays on Women, Equality, and Dependency. New York: Routledge.

Knox, Jeremy, Ben Williamson, and Sian Bayne. 2020. "Machine Behaviourism: Future Vision of 'Learnification' and 'Datafication' across Human and Digital Technologies." Learning, Media and Technology 45 (1): 31-45. https://doi.org/10.1080/17439884.2019.1623251.

Kraft, David P. 2011. "One Hundred Years of College Mental Health." Journal of American College Health 59 (6): 477-81. https://doi.org/10.1080/07448481.2011.569964.

Langlois, Ganaele and Greg Elmer. 2018. "Impersonal Subjectivation from Platforms to Infrastructures." Media, Culture \& Society 41 (2): 236-251.

https://doi.org/10.1177/0163443718818374

Lanzing, Marjolein. 2016. "The Transparent Self." Ethics and Information Technology 18 (1): 9-16. https://doi.org/ 10.1007/s10676-016-9396-y.

Lipson, Sarah Ketchen, Adam Kern, Daniel Eisenberg, and Alfiee M. Breland-Noble. 2018. "Mental Health Disparities among College Students of Color." Journal of Adolescent Health 63 (3): 348-56. https://doi.org/10.1016/j.jadohealth.2018.04.014.

Lipson, Sarah Ketchen, Emily G. Lattie, and Daniel Eisenberg. 2018. "Increased Rates of Mental Health Service Utilization by U.S. College Students: 10-year Populationlevel Trends (2007-2017)." Psychiatric Services 70 (1): 60-63.

https://doi.org/10.1176/appi.ps.201800332.

Lipson, Sarah Ketchen, Julia Raifman, Sara Abelson, and Sari L. Reisner. 2019. "Gender Minority Mental Health in the U.S.: Results of a National Survey on College Campuses." American Journal of Preventative Medicine 57 (3): 293-301. 
https://doi.org/10.1016/j.amepre.2019.04.025.

Liu, Cindy H., Courtney Stevens, Sylvia H.M. Wong, Miwa Yasui, and Justin A. Chen. 2019. "The Prevalence and Predictors of Mental Health Diagnoses and Suicide among U.S. College Students: Implications for Addressing Disparities in Service Use." Depression \& Anxiety 36 (1): 8-17. https://doi.org/10.1002/da.22830.

Lorde, Audre. 1988. A Burst of Light and Other Essays. London: Sheba Feminist Publishers.

Lupton, Deborah. 2013. "Understanding the Human Machine." IEEE Technology \& Society Magazine 32 (4): 25-30. https://doi.org/10.1109/MTS.2013.2286431.

. 2015. "Quantified Sex: A Critical Analysis of Sexual and Reproductive SelfTracking Using Apps." Culture Health \& Sexuality 17 (4): 440-53.

https://doi.org/10.1080/13691058.2014.920528.

— 2016a. "The Diverse Domains of Quantified Selves: Self-tracking Modes and Dataveillance." Economy and Society 45 (1): 101-22.

https://doi.org/10.1080.03085147.2016.1143726.

2016b. The Quantified Self. Cambridge, UK: Polity Press.

McGee, Ebony O., and David Stovall. 2015. "Reimagining Critical Race Theory in Education: Mental Health, Healing, and the Pathway to Liberatory Praxis."

Educational Theory 65 (5): 491-511. https://doi.org/10.1111/edth.12129.

_. 2016. "Black Students and Mental Health: An Emerging, Unseen Crisis." Insight into Diversity, August 17, 2016. https://www.insightintodiversity.com/blackstudents-and-mental-health-an-emerging-unseen-crisis/.

McLeod, Julie. 2012. "Vulnerability and the Neo-liberal Youth Citizen: A View from Australia." Comparative Education 48 (1): 11-26. https://doi.org/10.1080/03050068.2011.637760.

Mertz, Emily. 2018. "University of Alberta Students Get in Touch with Well-Being, Mental Health through WellTrack App." Global News, November 21, 2018.

https://globalnews.ca/news/4686918/mental-health-university-of-alberta-studentswelltrack-app/.

Montag, Ali. 2018. "This University Is Putting Amazon Echo Speakers in Every Dorm Room." CNBC, August 21, 2018. https://www.cnbc.com/2018/08/21/this-university-isputting-amazon-echo-speakers-in-every-dorm-room.html.

Moore, Phoebe V. 2018. The Quantified Self in Precarity: Work, Technology and What Counts. New York: Routledge.

Morozov, Evgeny. 2013. To Save Everything Click Here: Technology, Solutionism and 
the Urge to Fix Problems That Don't Exist. London: Penguin.

Newfield, Christopher. 2016. The Great Mistake: How We Wrecked Public Universities and How We Can Fix Them. Baltimore, MD: Johns Hopkins University Press.

Pew Research Center. 2019. "Mobile Fact Sheet: Mobile Phone Ownership over Time." June 12, 2019. https://www.pewresearch.org/internet/fact-sheet/mobile/.

Quinn, Mark. 2016. "Am I Blue? Memorial University Hosts Moodcheck Challenge." CBC, March 16, 2016. https://www.cbc.ca/news/canada/newfoundlandlabrador/moodcheck-challenge-app-memorial-unviersity-1.3492412.

Rajan, Kaushik Sunder. 2012. "Introduction: The Capitalization of Life and the Liveliness of Capital." In Lively Capital: Biotechnologies, Ethics, and Governance in Global Markets, edited by Kaushik Sunder Rajan, 1-41. Durham, NC: Duke University Press.

Read, Jason. 2010. "The Production of Subjectivity: From Transindividuality to the Commons." New Formations, no. 70, 113-31. https://doi.org/10.3898/NEWF.70.07.2010.

Roberts, Dorothy E. 2019. "Book Review: Digitizing the Carceral State." Harvard Law Review, no. 132, 1695-1728. https://harvardlawreview.org/2019/04/digitizing-thecarceral-state/.

Rosner, Rachel I. 2018. "Manualizing Psychotherapy: Aaron T. Beck and the Origins of Cognitive Therapy of Depression." European Journal of Psychotherapy \& Counselling 20 (1): 25-47. https://doi.org/10.1080/13642537.2017.1421984.

Sacks, Ethan. 2018. "Alexa Privacy Fail Highlights Risks of Smart Speakers." NBC News, May 26, 2018. https://www.nbcnews.com/tech/innovation/alexa-privacy-failhighlights-risks-smart-speakers-n877671.

Selwyn, Neil. 2014. Digital Technology and the Contemporary University: Degrees of Digitization. London: Routledge.

Simon, Caroline. 2017. "More and More Students Need Mental Health Services. But Colleges Struggle to Keep Up." USA Today, May 4, 2017. https://www.usatoday.com/story/college/2017/05/04/more-and-more-students-needmental-health-services-but-colleges-struggle-to-keep-up/37431099/.

So, Mirai, Sosei Yamaguchi, Sora Hashimoto, Mitsuhiro Sado, Furukawa A. Toshi, and Paul McCrone. 2013. "Is Computerised CBT Really Helpful for Adult Depression? A Meta-analytic Re-evaluation of CCBT for Adult Depression in Terms of Clinical Implementation and Methodological Validity." BMC Psychiatry, no. 13, 113-27. https://doi.org/10.1186/1471-244X-13-113.

Stahl, Titus. 2013. "What Is Immanent Critique?" SSRN Working Papers. 
http://ssrn.com/abstract=2357957.

Student Loan Hero. 2020. "A Look at the Shocking Student Loan Debt Statistics for 2020." Accessed January 25, 2021. https://studentloanhero.com/student-loan-debtstatistics/.

Vanderslot, Jodie. 2017. "Mental Health through WellTrack." Excalibur, December 1, 2017. https://excal.on.ca/mental-health-through-welltrack/.

Webster, David, and Nicola Rivers. 2019. "Resisting Resilience: Disrupting Discourses of Self-efficacy." Pedagogy, Culture \& Society 27 (4): 523-35.

https://doi.org/10.1080/14681366.2018.1534261.

WellTrack. 2020. "Clinicians \& Administrators." Accessed October 31, 2020. https://welltrack.com/for-higher-ed/.

Wernimont, Jacqueline. 2018. Numbered Lives: Life and Death in Quantum Media. Cambridge, MA: MIT Press.

Whitman, Madisson. 2020. "'We Called That a Behavior': The Making of Institutional Data." Big Data \& Society 7 (1): 1-13. https://doi.org/10.1177/2053951720932200.

Wilder, Craig Steven. 2013. Ebony and Ivy: Race, Slavery, and the Troubled History of America's Universities. New York: Bloomsbury Press.

Williams, Frankwood Earl. 1921. "Mental Hygiene and the College Student." Mental Hygiene, no. 5, 283-301.

Williamson, Ben. 2018. "The Hidden Architecture of Higher Education: Building a Big Data Infrastructure for the 'Smarter University. '" International Journal of Higher Education 15 (12): 1-26. https://doi.org/10.1186/s41239-018-0094-1.

- 2019. "Psychodata: Disassembling the Psychological, Economic, and Statistical Infrastructure of 'Socio-emotional Learning.'" Journal of Education Policy, 1-26. https://doi.org/10.1080/02680939.2019.1672895.

- 2020. "Datafication and Automation in Higher Education during and after the Covid-19 Crisis." code acts in education (blog). May 6, 2020.

https://codeactsineducation.wordpress.com/2020/05/06/datafication-automation-hecovid19-crisis/.

Wolters, Raymond. 1975. The New Negro on Campus: Black College Rebellions of the 1920s. Princeton, NJ: Princeton University Press.

Zalcmanis-Lai, Ophelie. 2016. "Exclusive: University Set to Introduce Online Mental Health Platform to Students." Ryersonian, April 9, 2016.

https://ryersonian.ca/exclusive-university-set-to-introduce-online-mental-healthplatform-to-students/. 


\section{Author Bio}

Lindsay Weinberg is a clinical assistant professor in the Honors College at Purdue University. Her research and teaching are at the intersection of science and technology studies, media studies, and feminist studies, with an emphasis on the social and ethical impacts of digital technology. Her work has appeared in Lateral, Westminster Papers in Communication and Culture, Impost: A Journal of Critical and Creative Work, and Catalyst: Feminism, Theory, Technoscience. 